\title{
Impact of cervicothoracic region stereotactic spine radiosurgery on adjacent organs at risk
}

\author{
Mayur Sharma, MD, ${ }^{1}$ Elizabeth E. Bennett, MD, ${ }^{1}$ Gazanfar Rahmathulla, MD, ${ }^{4}$ \\ Samuel T. Chao, MD, ${ }^{2}$ Hilary K. Koech, BS, ${ }^{1}$ Stephanie N. Gregory, BS, ${ }^{1}$ Todd Emch, MD, ${ }^{3}$ \\ Anthony Magnelli, MS, ${ }^{2}$ Antonio Meola, MD, ${ }^{1}$ John H. Suh, MD, ${ }^{2}$ and Lilyana Angelov, MD' \\ Departments of ${ }^{1}$ Neurosurgery and ${ }^{2}$ Radiation Oncology, Rose Ella Burkhardt Brain Tumor and Neuro-Oncology Center, \\ Neurological Institute, and ${ }^{3}$ Imaging Institute, Section of Neuroradiology, Cleveland Clinic, Cleveland, Ohio; and ${ }^{4}$ Department of \\ Neurosurgery, University of Florida, Jacksonville, Florida
}

OBJECTIVE Stereotactic radiosurgery (SRS) of the spine is a conformal method of delivering a high radiation dose to a target in a single or few (usually $\leq 5$ ) fractions with a sharp fall-off outside the target volume. Although efforts have been focused on evaluating spinal cord tolerance when treating spinal column metastases, no study has formally evaluated toxicity to the surrounding organs at risk (OAR), such as the brachial plexus or the oropharynx, when performing SRS in the cervicothoracic region. The aim of this study was to evaluate the radiation dosimetry and the acute and delayed toxicities of SRS on OAR in such patients.

METHODS Fifty-six consecutive patients (60 procedures) with a cervicothoracic spine tumor involving segments within C5-T1 who were treated using single-fraction SRS between February 2006 and July 2014 were included in the study. Each patient underwent CT simulation and high-definition MRI before treatment. The clinical target volume and OAR were contoured on BrainScan and iPlan software after image fusion. Radiation toxicity was evaluated using the common toxicity criteria for adverse events and correlated to the radiation doses delivered to these regions. The incidence of vertebral body compression fracture (VCF) before and after SRS was evaluated also.

RESULTS Metastatic lesions constituted the majority $(n=52$ [93\%]) of tumors treated with SRS. Each patient was treated with a median single prescription dose of $16 \mathrm{~Gy}$ to the target. The median percentage of tumor covered by SRS was $93 \%$ (maximum target dose $18.21 \mathrm{~Gy}$ ). The brachial plexus received the highest mean maximum dose of $17 \mathrm{~Gy}$, followed by the esophagus (13.8 Gy) and spinal cord (13 Gy). A total of 14 toxicities were encountered in 56 patients $(25 \%)$ during the study period. Overall, $14 \%(n=8)$ of the patients had Grade 1 toxicity, $9 \%(n=5)$ had Grade 2 toxicity, $2 \%(n=1)$ had Grade 3 toxicity, and none of the patients had Grade 4 or 5 toxicity. The most common (12\%) toxicity was dysphagia/odynophagia, followed by axial spine pain flare or painful radiculopathy (9\%). The maximum radiation dose to the brachial plexus showed a trend toward significance $(p=0.066)$ in patients with worsening post-SRS pain. De novo and progressive VCFs after SRS were noted in 3\% (3 of 98 ) and $4 \%$ (4 of 98 ) of vertebral segments, respectively.

CONCLUSIONS From the analysis, the current SRS doses used at the Cleveland Clinic seem safe and well tolerated at the cervicothoracic junction. These preliminary data provide tolerance benchmarks for OAR in this region. Because the effect of dose-escalation SRS strategies aimed at improving local tumor control needs to be balanced carefully with associated treatment-related toxicity on adjacent OAR, larger prospective studies using such approaches are needed. https://thejns.org/doi/abs/10.3171/2016.10.FOCUS16364

KEY WORDS spine radiosurgery; organs at risk; cervicothoracic; toxicity

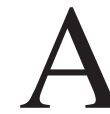
CCORDING to the National Cancer Institute Surveillance, Epidemiology, and End Results (SEER 17 registry) database, the number of new cancer patients (across all ages and sites) is likely to be 2.8 million in 2050, compared with 1.62 million in $2010 . .^{25,57}$ With ad- vances in the management of a variety of systemic cancers, there has been an improvement in overall patient survival and an anticipated associated increase in the incidence of metastatic disease. Approximately $40 \%-50 \%$ of these patients with systemic cancer are likely to develop bony spi-

ABBREVIATIONS EBRT = external-beam radiation therapy; IMRT = intensity-modulated radiation therapy; OAR = organ(s) at risk; RT = radiation therapy; RTOG = Radiation Therapy Oncology Group; SRS = stereotactic radiosurgery; VB = vertebral body; VCF = vertebral body compression fracture.

SUBMITTED September 1, 2016. ACCEPTED October 12, 2016.

INCLUDE WHEN CITING DOI: 10.3171/2016.10.FOCUS16364. 
nal metastases, ${ }^{56,58}$ and $10 \%$ to $20 \%$ of them are likely to suffer symptoms of spinal cord compression. ${ }^{29,46,48}$ Axial back pain is the most frequent presenting symptom in patients with osseous spinal metastasis; $;{ }^{56}$ other clinical manifestations include radiculopathy and symptoms of spinal cord compression (motor weakness, sensory and sphincter disturbances), which have a significant effect on quality of life in patients with spinal metastasis. Early and aggressive management of spinal metastases has been shown to result in the alleviation of axial back pain and other neurological symptoms and an improvement in overall quality of life. ${ }^{23}$

In 1996, Hamilton et al. ${ }^{21}$ pioneered the use of conventional linear accelerators to deliver stereotactic radiosurgery (SRS) for the treatment of spine lesions. Furthermore, advances in neuroimaging techniques, software applications, target tracking, and a variety of radiationdelivery platforms have led to the widespread use of SRS in managing patients with extracranial lesions, including spinal metastasis. ${ }^{7,26,37,38,46,50}$ Also, 3D treatment planning for radiation therapy (RT) has enabled quantitative correlation of radiation dosimetric parameters with clinical outcomes and provided a better understanding of the treatment profile. Spine SRS provides precise and conformal high-dose radiation to a tumor in a single or few (usually $\leq 5$ ) fractions with a sharp fall-off outside the target volume. Although higher radiation doses have been shown to improve local control rates ${ }^{32}$ they also increase the risk of radiation-induced injury to surrounding critical structures at the corresponding level. ${ }^{18,19}$

There is paucity of literature regarding guidelines for predicting the relative safety of treatment plans in regard to surrounding organs at risk (OAR). ${ }^{35}$ Although efforts have been focused on evaluating spinal cord tolerance when treating spinal column metastases, no recommendations exist for partial-volume tolerance of the nearby OAR, such as the brachial plexus and oropharyngeal structures (larynx, trachea, and esophagus), during SRS in the cervicothoracic region. The aim of our study was to evaluate the radiation dosimetry and acute and delayed effects (toxicity) of SRS on the spinal cord, larynx, trachea, esophagus, and brachial plexus in 56 consecutively treated patients with a cervicothoracic spine tumor. We also evaluated the incidence of vertebral body (VB) compression fractures (VCFs) after SRS in these patients.

\section{Methods \\ Patient Characteristics}

After being approved by the IRB at the Cleveland Clinic, this retrospective study was performed for patients treated at the Cleveland Clinic from February 2006 to July 2014. Clinical data were collected retrospectively from the electronic medical records of the patients who underwent single-fraction SRS to the cervicothoracic spine (between C-5 and T-1). All consecutively treated patients with a lesion that involved 1 or more contiguous spinal segments between $\mathrm{C}-5$ and $\mathrm{T}-1$, with or without spinal cord compression, were included in the study. Patients who had undergone previous external-beam radiotherapy (EBRT) to the cervicothoracic region or SRS involving other remote spinal levels were not excluded from the study. Patients who had undergone previous SRS in the C5-T1 region were excluded. A total of 56 patients met the eligibility criteria. Patient follow-up typically occurred 1 month after SRS and subsequently every 3 months to assess treatment response and adverse effects of therapy.

\section{Image Acquisition and Analysis}

Both CT simulation scans (1.5-mm-thick contiguous slices) and high-definition MR images (1.5-mm slice thickness) (Siemens AG) were acquired in all patients. Cervical spine MRI with axial T1-weighted, T2-weighted, and short $\mathrm{T} 1$ inversion-recovery images was performed for planning. All patients underwent CT simulation in the supine position, and a 5-point mask (Orfit Industries) was used to immobilize the spine and ensure optimal reproducibility of the spinal anatomy on the day of treatment. MR images were then fused to the CT simulation scan using iPlan software (Brainlab AG) to delineate the tumor and critical organs.

\section{Radiosurgical Target, OAR Volumes, and Toxicity}

The clinical target volume was defined according to the guidelines proposed by the International Spine Radiosurgery Consortium ${ }^{11}$ and included VBs, lamina, pedicles, and spinous processes, depending on the extent of tumor involvement in these elements. When present, paraspinal or epidural extension of the tumor seen on imaging was treated along with the involved spinal segments.

The OAR contoured in our study included the spinal cord, larynx, trachea, esophagus, and brachial plexus. The spinal cord was contoured 2 slices above and 2 slices below (3-4 $\mathrm{mm}$ in each direction) the superior- and inferiormost extent of the spinal column target. ${ }^{43}$ The brachial plexus was contoured as described by Hall et al., ${ }^{20}$ and other OAR were contoured as described by Eisbruch et al. ${ }^{14}$ : the larynx was contoured as a single structure from the beginning of the epiglottis to the superior edge of the cricoid cartilage, the trachea was contoured from the inferior edge of the cricoid to approximately $1-2 \mathrm{~cm}$ inferior to the tracheal bifurcation, and the esophagus was contoured from the inferior edge of the cricoid to approximately $1-2 \mathrm{~cm}$ inferior to the tracheal bifurcation at its lowest point. OAR and tumor contours were verified for accuracy by the treating radiation oncologist and neurosurgeon and, when there was possible uncertainty, a radiologist, thus maintaining uniformity in terms of contours in all our patients (Figs. 1 and 2).

Acute radiation toxicity was evaluated using the National Cancer Institute's common toxicity criteria for adverse events, and results of that evaluation were recorded for each patient during follow-up. ${ }^{3}$ Acute or delayed toxicity to each of the OAR was evaluated and correlated to the radiation doses delivered.

\section{Radiosurgical Procedure}

A majority of spine SRSs were performed using a Novalis classic Shaped-Beam, Novalis Tx (Brainlab), or Edge (Varian Medical Systems, Inc.) radiosurgery system, as described in other reports. ${ }^{31,40,61,62}$ Treatment 


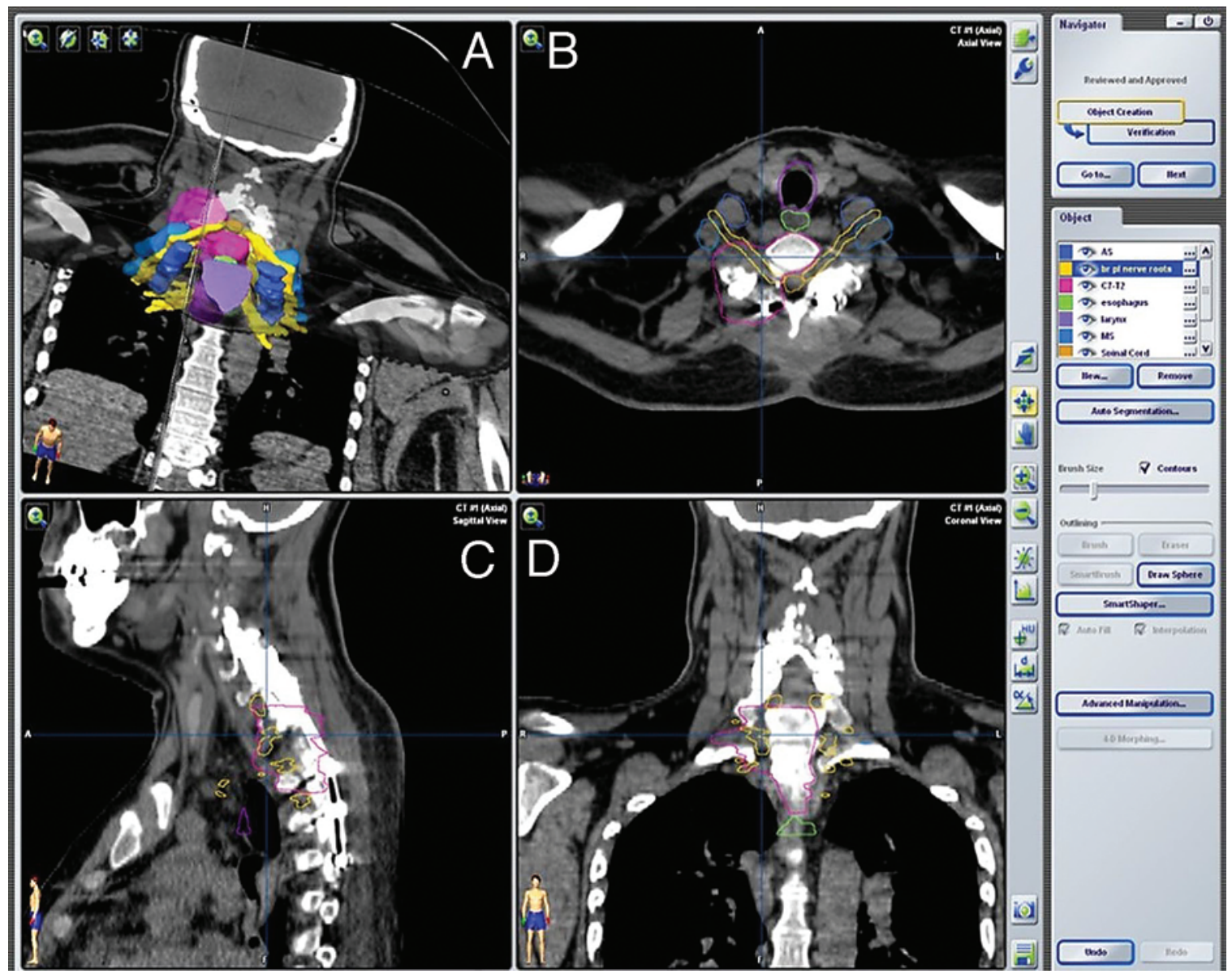

FIG. 1. CT images of contours of tumor volume and OAR on a 3D reconstruction image (A) and in axial (B), sagittal (C), and coronal (D) views in a patient with a cervicothoracic tumor.

planning was performed using BrainScan (Brainlab) and iPlan (Brainlab) or Pinnacle (Philips Radiation Oncology Systems) software. The ExacTrac system (Brainlab) or cone-beam CT scans were used for frameless imageguided positioning and targeting before treatment deliv- ery. ${ }^{28,42}$ The ExacTrac system involves 2 infrared cameras that track the position of 6-7 infrared markers applied asymmetrically to the patient's body, which aids in localization. ${ }^{60}$

The conformality index (prescription isodose volume/
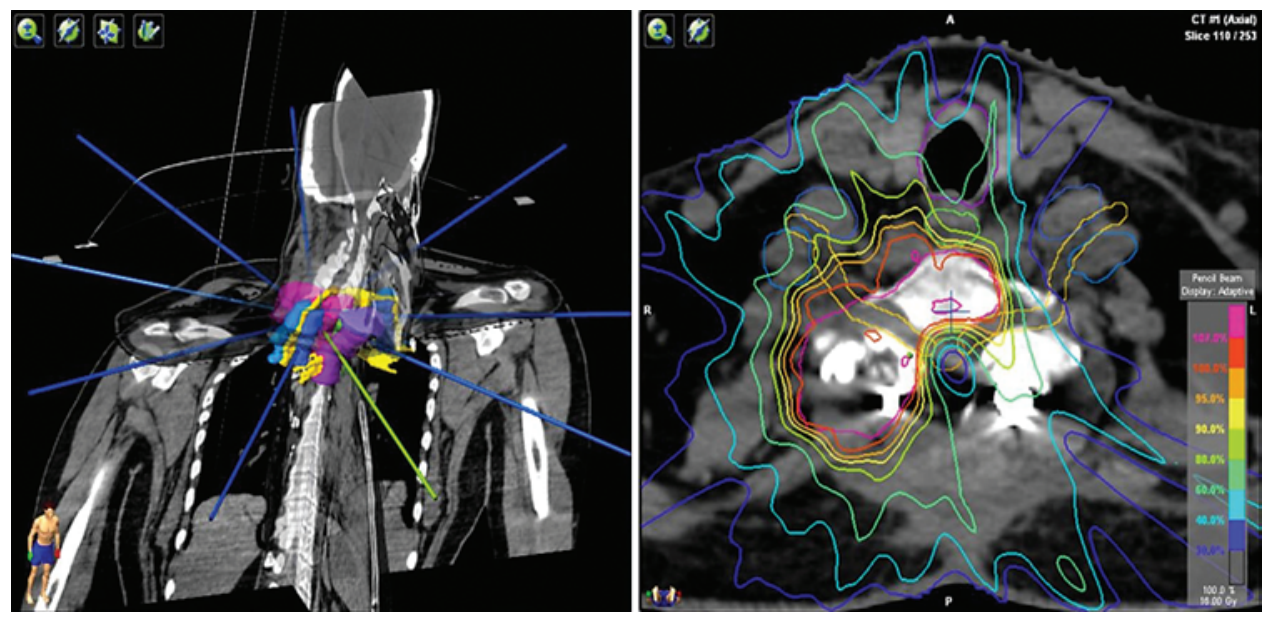

FIG. 2. CT image (axial view) of the isodose distribution (right) and 3D CT reconstruction image of beam projections to the tumor volume (left) in a patient with a cervicothoracic tumor. 
target volume) and heterogeneity index (maximum dose/ prescribed dose) were calculated for each patient. The prescription dose at the Cleveland Clinic increased gradually from $14 \mathrm{~Gy}$ (initial part of the series) to $16 \mathrm{~Gy}$ after emerging data on the safety and efficacy of SRS; therefore, the median prescription dose in this cohort was 16 Gy. Other dosimetric parameters and planning techniques have remained largely the same.

An inverse-planning algorithm built into the computational software (Brainlab) and Pinnacle (Philips Radiation Oncology Systems) was used to achieve the desired dose distribution. The resultant dose-volume histograms for the target and the OAR were used to evaluate the treatment plan. The dose parameters used to evaluate toxicity were the radiation dose (Gy) to 0.1-, 1-, 2-, and 5- $\mathrm{cm}^{3}$ of OAR. Volumes of OAR that received more than 10 Gy of radiation and the mean maximum dose received by the OAR were also recorded.

\section{Vertebral Body Compression Fracture Data}

VCF was assessed at the anterior, middle, and posterior body levels as described by Adams et al. ${ }^{1}$ using preprocedure and postprocedure sagittal MRI scans. The reference VB height measurement was taken from the closest/adjacent normal VB. A decrease in VB height of 20\%-25\% in any of the 3 columns (anterior, middle, and/or posterior) was recorded as a Grade $1 \mathrm{VCF}$, a $25 \%-40 \%$ decrease in the anterior, middle, and/or posterior height as a Grade 2 VCF, and a $>40 \%$ decrease in the anterior, middle, and/or posterior height as a Grade 3 VCF. The highest grade collapse at a particular vertebral level was used in the analysis.

\section{Statistical Analysis}

Microsoft Excel and SPSS v20 (IBM, Inc.) were used for statistical analysis. An independent-sample t-test was used to compare means between the variables. A 2-tailed $\mathrm{p}$ value of $<0.05$ was considered significant. Values for patient characteristics were documented as mean \pm SD .

\section{Results}

\section{Patient Demographics and Disease Characteristics}

A total of 56 patients (60 SRS procedures) comprising 143 VB segments treated were included in our study (see Table 1 for baseline characteristics). The majority of patients in our study were male (39 [70\%]), and the mean age of our patients was $64.29 \pm 12.70$ years. Metastatic tumors constituted the majority (52 [93\%]) of tumors, and primary tumors, which were treated with SRS, were found in 3 patients (5\%). Among the metastatic tumors, renal cell carcinoma was the most common pathology (27\%), followed by non-small cell lung carcinoma (23\%).

A majority (71\%) of the patients had progressive systemic disease at the time of SRS. Furthermore, $41 \%$ (23) of the patients had undergone previous chemotherapy within 1 month of SRS, 39\% (22) of the patients had undergone previous surgery at the level of SRS, and 25\% (14) of the patients had undergone previous EBRT involving the cervicothoracic region before SRS.

The most frequently treated spinal segments were T-1 (22\%) and C-7 (20\%), and the median pre-SRS tumor vol-
TABLE 1. Patient demographics and tumor characteristics

\begin{tabular}{|c|c|}
\hline Variable & Total $^{*}$ \\
\hline \multicolumn{2}{|l|}{ Sex (no. [\%]) } \\
\hline Female & $17(30.35)$ \\
\hline Male & $39(69.64)$ \\
\hline Age (mean \pm SD; median) (yrs) & $64.29 \pm 12.70 ; 65.5$ \\
\hline \multicolumn{2}{|l|}{ Primary tumor type (no. [\%]) } \\
\hline Metastasis, RCC & $15(26.78)$ \\
\hline Metastasis, NSCLC & $13(23.21)$ \\
\hline Metastasis, prostate cancer & $5(8.93)$ \\
\hline Metastasis, breast cancer & $3(5.36)$ \\
\hline Metastasis, head, neck SCC & $3(5.36)$ \\
\hline Other† & $17(30.36)$ \\
\hline \multicolumn{2}{|l|}{ Status of systemic disease at SRS (no. [\%]) } \\
\hline Progressive & $40(71.43)$ \\
\hline Controlled & $14(25)$ \\
\hline $\begin{array}{l}\text { Patients receiving EBRT as initial treatment } \\
\text { (no. [\%]) }\end{array}$ & $14(25)$ \\
\hline $\begin{array}{l}\text { Patients w/ previous op at the site of SRS } \\
\text { (no. [\%]) }\end{array}$ & $22(39.29)$ \\
\hline $\begin{array}{l}\text { Patients w/ previous systemic therapy w/in } 1 \\
\text { mo of SRS (no. [\%]) }\end{array}$ & $23(41.07)$ \\
\hline KPS score at SRS (median) & 80 \\
\hline \multicolumn{2}{|l|}{ Spinal level treated (143 total levels) (no. [\%]) } \\
\hline C-5 & $19(13.29)$ \\
\hline C-6 & $18(12.6)$ \\
\hline C-7 & $29(20.28)$ \\
\hline $\mathrm{T}-1$ & $32(22.38)$ \\
\hline Total & $98(68.53)$ \\
\hline Pre-SRS tumor vol (median $\pm \mathrm{SD})\left(\mathrm{cm}^{3}\right)$ & $47.79 \pm 61.62$ \\
\hline Pre-SRS max diameter (median \pm SD) $(\mathrm{cm})$ & $6.8 \pm 2.34$ \\
\hline Overall follow-up (mean; median \pm SD) (mos) & $10.7 ; 4.12 \pm 16.77$ \\
\hline Overall survival (mean; median \pm SD) (mos) & $22.88 ; 7.5 \pm 32.14$ \\
\hline \multicolumn{2}{|l|}{ Final outcome at last follow-up (no. [\%]) } \\
\hline Deceased & $45(80.36)$ \\
\hline Alive & $11(19.64)$ \\
\hline
\end{tabular}

KPS = Karnofsky Performance Scale; NSCLC = non-small cell lung cancer; $\mathrm{RCC}=$ renal cell carcinoma; $\mathrm{SCC}=$ squamous cell carcinoma .

* Total of 56 patients ( 60 procedures).

$\dagger$ Other includes hepatocellular carcinoma, paraganglioma, small cell lung cancer, colon, sarcoma, pancreatic, plasmacytoma, chordoma, large cell lung cancer, spindle cell cancer, esophagus, arteriovenous malformation, or esthesioneuroblastoma.

ume was $47.79 \mathrm{~cm}^{3}$. Median overall survival after treatment was 7.5 months, and a majority (45 [80\%]) of the patients were deceased at the mean follow-up of 10.7 months.

\section{Treatment Characteristics}

The median dose, number of fractions, and intensitymodulated RT (IMRT) fields were $16 \mathrm{~Gy}, 1$, and 7, respectively. The median percentage of tumor covered by SRS was 93\%; the maximum target dose was $18.21 \mathrm{~Gy}$, and the median conformality index was 1.42 (Table 2). 
TABLE 2. Treatment characteristics in patients who underwent SRS for a cervicothoracic tumor

\begin{tabular}{lc}
\hline \multicolumn{1}{c}{ Variable } & Value \\
\hline Median dose (Gy) & 16 \\
\hline Median no. of fractions & 1 \\
\hline Median no. of IMRT fields & 7 \\
\hline Median \% of tumor covered & 92.75 \\
\hline Median target dose (Gy) & 10.11 \\
\hline Min & 18.21 \\
\hline Max & 1.42 \\
\hline Median conformality index & 1.16 \\
\hline Median homogeneity index
\end{tabular}

\section{Radiation Dose Received by OAR}

Specific OAR volumes treated, radiation doses received, and point maximum doses are listed in Table 3. The larynx was the structure that had the highest volume in the cervicothoracic region exposed to radiation with SRS, followed by the trachea and brachial plexus, whereas the spinal cord received the largest mean dose of $6.5 \mathrm{~Gy}$, followed by the esophagus (5.84 Gy) and brachial plexus (5.7 Gy). However, the brachial plexus received the highest mean point maximum dose of $17 \mathrm{~Gy}$, followed by the esophagus (13.9 Gy) and spinal cord (13 Gy). In terms of mean radiation dose to the $0.1-$ and $1-\mathrm{cm}^{3}$ volume, the brachial plexus received the highest dose, followed by the esophagus and spinal cord.

\section{Clinical Toxicities and Vertebral Compression}

The treatment was well tolerated in all patients, and the majority of toxicities were self-limited when they occurred. A total of 14 toxicities were encountered by 56 (25\%) patients in the study period. Fourteen percent (8) of the patients had Grade 1 toxicity, 9\% (5) had Grade 2 toxicity, $2 \%$ (1) had Grade 3 toxicity, and none of the patients had Grade 4 or 5 toxicity (Fig. 3). The most common post-SRS-related toxicity was dysphagia, which was noted in 7 (13\%) patients. Two of these patients had Grade 2 toxicity that resolved with BMX (Benadryl, Maalox, and Xylocaine) elixir, and another 5 patients had Grade 1 toxicity that resolved spontaneously in the follow-up period.

The second-most common post-SRS toxicity noted in our study was an increase in axial spine pain flares or painful radiculopathy (9\% [5 patients]), which resolved in all cases within 1-14 days after a steroid treatment (dexa- methasone). A Grade 3 toxicity was seen in only 1 patient, who initially presented with infiltrating ductal carcinoma metastasis to T-1. She underwent a T-1 corpectomy, anterior cervical plating (C7-T2), and posterior $\mathrm{C} 4-\mathrm{T} 5$ fusion for this lesion; however, she developed persistent upper thoracic pain and dysphagia immediately after surgery. She subsequently underwent SRS for the residual tumor 6 weeks after the primary surgery. Her dysphagia persisted after SRS, and esophageal stricture was diagnosed 9 months after the SRS. This patient underwent successful balloon dilation 9 months after SRS, and results of a biopsy performed at the time of dilation were consistent with radiation-type esophageal injury. The etiology of this complication is potentially multifactorial; thus, considering it as solely a radiation injury might not be appropriate. However, for the purpose of this study and with the pathological tissue obtained, we considered this complication an SRS treatment-related toxicity with the caveat that it is conceivable that patients who have had combination surgery and radiosurgery in the cervicothoracic region can represent a population at risk for Grade 3 toxicity to the esophagus.

One patient with renal carcinoma metastatic to C-5 who had undergone previous radiation and surgery (C-5 corpectomy and fusion) developed hoarseness and dysphonia (Grade 1 toxicity) after spine surgery; this toxicity gradually improved during the follow-up period. His hoarseness subsequently worsened after SRS and then gradually resolved over the next 2 months. No significant nausea/fatigue, myelitis, brachial plexopathy, or neurological injury attributable to SRS was noted in our study (Table 4).

There was no significant association between the mean and maximum radiation doses to the esophagus, larynx, trachea, and spinal cord or the incidence of dysphagia, hoarseness, and radiculopathy, respectively ( $\mathrm{p}>$ $0.05)$. However, the maximum dose to the brachial plexus showed a trend toward significance $(p=0.066)$ in patients with worsening of pain or painful radiculopathy (Fig. 3).

De novo and progressive VCFs after SRS were noted in 3\% (3 of 98) and 4\% (4 of 98) of the vertebral segments treated, respectively (Table 5). A median interval of 4.1 months (mean 4.84 months) between treatment and diagnosis of VCF was noted; $71 \%$ (5 of 7) of the VCFs were diagnosed within 4 months of treatment. Of the patients who had a de novo fracture, 2 patients developed a $>40 \%$ decrease (Grade 3 VCF) after SRS, and the other patient developed a Grade 2 VCF after SRS. Of the patients with progression of a VCF, all of them initially had a Grade 2 VCF that progressed to a Grade 3 VCF after SRS. An

TABLE 3. Extent of radiation dose received by OAR

\begin{tabular}{lcccccccc}
\hline \multicolumn{1}{c}{ OAR } & $\begin{array}{c}\text { Mean } \\
\text { Vol }\left(\mathrm{cm}^{3}\right)\end{array}$ & $\begin{array}{c}\text { Mean Dose } \\
(\mathrm{Gy}) \text { at } 0.1 \mathrm{~cm}^{3}\end{array}$ & $\begin{array}{c}\text { Mean Dose } \\
(\mathrm{Gy}) \text { at } 1 \mathrm{~cm}^{3}\end{array}$ & $\begin{array}{c}\text { Mean Dose } \\
(\mathrm{Gy}) \text { at } 2 \mathrm{~cm}^{3}\end{array}$ & $\begin{array}{c}\text { Mean Dose } \\
(\mathrm{Gy}) \text { at } 5 \mathrm{~cm}^{3}\end{array}$ & $\begin{array}{c}\text { Mean } \\
\text { Dose }(\mathrm{Gy})\end{array}$ & $\begin{array}{c}\text { Vol at } 10 \\
\mathrm{~Gy}\left(\mathrm{~cm}^{3}\right)\end{array}$ & $\begin{array}{c}\text { Mean Max } \\
\text { Dose }(\mathrm{Gy})\end{array}$ \\
\hline Spinal cord & 5.351 & 11.172 & 8.203 & 6.307 & 3.242 & 6.505 & 0.449 & 13.060 \\
\hline Brachial plexus & 21.530 & 16.122 & 14.051 & 12.509 & 8.903 & 5.677 & 4.986 & 17.016 \\
\hline Larynx & 40.058 & 9.869 & 8.200 & 7.115 & 5.537 & 3.423 & 2.702 & 11.102 \\
\hline Trachea & 29.145 & 8.721 & 7.196 & 6.415 & 5.031 & 3.566 & 2.346 & 9.575 \\
\hline Esophagus & 10.643 & 12.874 & 10.865 & 8.725 & 5.267 & 5.835 & 3.506 & 13.875 \\
\hline
\end{tabular}



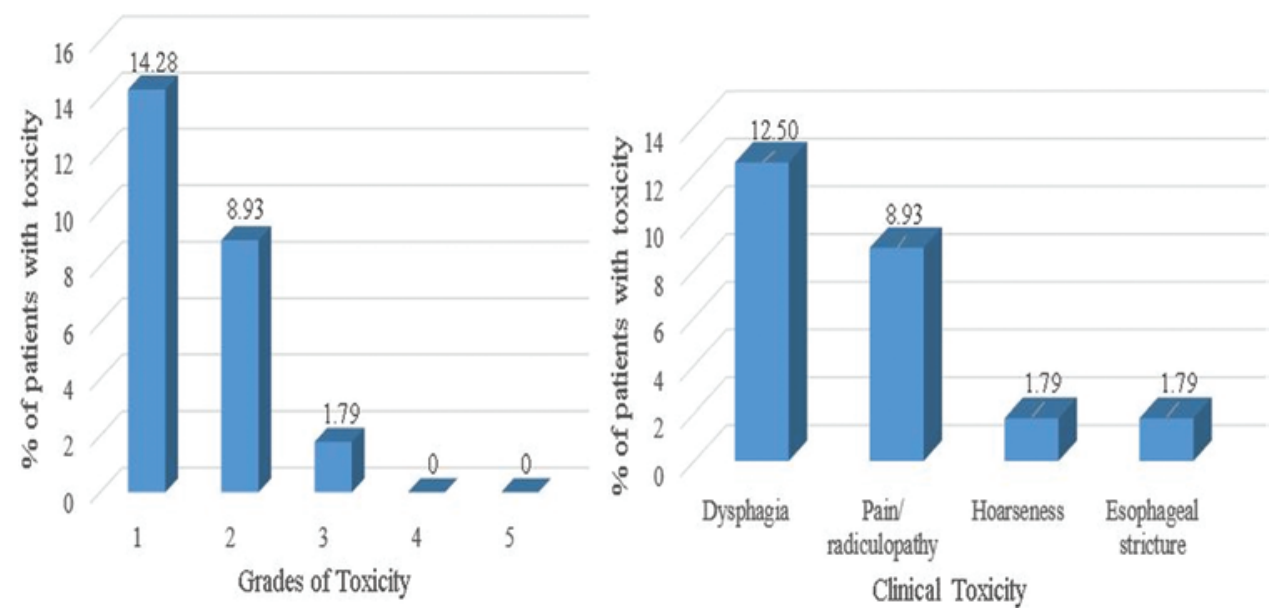

FIG. 3. Incidence of grades of clinical toxicities (left) and individual clinical toxicities (right) after SRS in patients with a cervicothoracic tumor.

anterior column VCF was found in $11 \%$ of vertebral levels both before and after SRS. Grade 3 VCF was noted in 5 (5\%) vertebral levels before SRS compared with 10 vertebral levels (10.20\%) after SRS. No follow-up imaging was available for 4 patients (with 9 vertebral levels) after SRS.

\section{Discussion}

The cervicothoracic region is surrounded by many critical structures, and radiation-induced injury to these structures can lead to significant morbidity in patients. Therefore, to avoid dose-related complications such as brachial plexopathy, esophagitis, dysphagia, esophageal perforation, or myelopathy when treating patients with cervicothoracic lesions, it is necessary to delineate the surrounding critical OAR and minimize radiation doses to these organs. ${ }^{12}$ Currently available IMRTs offer precise and conformal high-dose radiation delivery, which reduces the incidence of toxicity and improves local/regional disease control..$^{53}$ Although, radiation-induced myelopathy is the most devastating toxicity, radiation-induced toxicities to surrounding OAR cannot be overemphasized, especially with significant dose escalation. The majority of published studies focused on the spinal cord as an OAR, but a paucity of literature focused on the dose tolerances of the OAR in patients undergoing SRS for cervicothoracic tumors exists. ${ }^{16,27,34,59}$ Also, the tolerance of these organs has to be redefined in terms of a partial-volume effect to be applicable to SRS. ${ }^{43}$ The results of our study add to the literature regarding the dose tolerances of OAR in this region and can be considered as a benchmark in future dose-escalation strategies to ensure improved local disease control while minimizing toxicity. ${ }^{9,22,36}$

\section{Radiation-Induced Myelopathy}

From a large series of 393 patients (500 lesions) with spinal metastasis (73 cervical tumors) treated with SRS, Gerszten et al ${ }^{16}$ reported a long-term tumor-control rate of $90 \%$ when a mean maximum tumor dose of 20 Gy (range 12.5-25 Gy) was administered, and they reported no significant radiation-induced toxicities. Jin et al. ${ }^{27}$ presented a series of 196 patients (270 lesions; $11 \%$ cervical tumors) and reported no radiation-induced acute toxicities after SRS for spinal metastasis when a mean dose of $14.8 \mathrm{~Gy}$ was administered. Yamada et al. ${ }^{59}$ reported that patients who had received $>24$ Gy of radiation in a single session achieved better local tumor-control rates and showed no evidence of myelopathy or radiculopathy. Acute Grade 1-2 skin reactions were noted in 3 patients in this study. Another study reported that $<15$ Gy of radiation to the entire planning target volume resulted in a higher probability of recurrence and no reported incidence of myelopathy (maximum point dose 12-14 Gy)..$^{34}$ Ryu et al. ${ }^{43}$ reported a single case of radiation-induced spinal cord injury 13 months after spine SRS in 177 patients (230 lesions, 37 cervical lesions); in that patient, $0.32 \%\left(0.06 \mathrm{~cm}^{3}\right)$ of the spinal cord volume was within $80 \%$ isodose line (maximum point dose 14.6 Gy).$^{43}$ Gibbs et al. ${ }^{17}$ reported radiation doses of $>8$ Gy to the spinal cord in half of the patients who developed myelopathy (6 of 1075) after SRS in a large series of 1075 patients with a benign or malignant spine tumor.

Therefore, it is critical to strike a fine balance between delivering a high cytotoxic dose of radiation to the tumor while preserving the surrounding structures. Studies have found that 14 Gy of radiation to a single voxel on the spinal cord or 10 Gy to $10 \%$ of the spinal cord volume is usually

TABLE 4. Extent of clinical toxicities

\begin{tabular}{llc}
\hline \multicolumn{1}{c}{ Clinical Toxicity } & No. (\%) & $\begin{array}{c}\text { Highest Grade of Toxicity } \\
\text { (CTCAE 4.0) }\end{array}$ \\
\hline Dysphagia & $7(12.5)$ & 2 \\
\hline Pain/radiculopathy & $5(8.93)$ & 2 \\
\hline Hoarseness & $1(1.79)$ & 1 \\
\hline Esophageal stricture* & $1(1.79)$ & 3 \\
\hline CTCAE = common toxicity criteria for adverse events. \\
* This patient had undergone previous surgery (anterior T-1 corpectomy and \\
anterior cervical plating from C-7 to T-2) and developed a soft-tissue infection \\
that was treated before SRS.
\end{tabular}


TABLE 5. Extent of VCF before and after SRS

\begin{tabular}{|c|c|c|c|c|}
\hline VCF & $\begin{array}{c}\text { Before SRS } \\
(n=98)(n o .[\%])\end{array}$ & $\begin{array}{c}\text { Pre-SRS Decrease in VCH in } \\
\text { Descending Order (no. of patients) }\end{array}$ & $\begin{array}{c}\text { After SRS } \\
(n=98)(n o .[\%])\end{array}$ & $\begin{array}{c}\text { Post-SRS Decrease in VCH in } \\
\text { Descending Order (no. of patients) }\end{array}$ \\
\hline No decrease in VB height & $70(71.43)$ & - & $62(63.27)$ & - \\
\hline Grade 1 & $3(3.06)$ & $A(3)$ & $3(3.06)$ & $A(3)$ \\
\hline Grade 2 & $6(6.12)$ & AM, M (2), AMP (2), MAP & $1(1.02)$ & $M(1)$ \\
\hline Grade 3 & $5(5.10)$ & APM, AMP, MAP, MA, M & $10(10.20)$ & A, MP (2), AM, MA, MAP (3), AMP, MAP \\
\hline Previous cage at the site of SRS & $13(13.27)$ & - & $13(13.27)$ & - \\
\hline \multicolumn{4}{|c|}{ VCF \& Involvement of Vertebral Columns } & No. $(\%)$ \\
\hline \multicolumn{4}{|c|}{ De novo VCF after SRS at median interval of 5.43 mos } & $3 / 98(3.06)$ \\
\hline \multicolumn{4}{|c|}{ Progression of VCF after SRS, Grade 2 progressed to Grade 3 at median interval of 3.5 mos } & $4 / 98(4.08)$ \\
\hline \multicolumn{5}{|c|}{ Individual involvement of vertebral columns before SRS } \\
\hline \multicolumn{3}{|c|}{ A } & \multicolumn{2}{|r|}{$11 / 98(11.22)$} \\
\hline \multicolumn{3}{|l|}{ M } & \multicolumn{2}{|r|}{$11 / 98(11.22)$} \\
\hline \multicolumn{3}{|l|}{$\mathrm{P}$} & \multicolumn{2}{|r|}{$6 / 98(6.12)$} \\
\hline \multicolumn{5}{|c|}{ Individual involvement of vertebral columns after SRS } \\
\hline \multicolumn{3}{|c|}{ A } & \multicolumn{2}{|r|}{$11 / 98(11.22)$} \\
\hline \multicolumn{3}{|l|}{ M } & \multicolumn{2}{|r|}{$10 / 98(10.20)$} \\
\hline \multicolumn{3}{|l|}{$P$} & \multicolumn{2}{|r|}{$7 / 98(7.14)$} \\
\hline
\end{tabular}

$\mathrm{A}=$ anterior; $\mathrm{M}=$ middle; $\mathrm{P}=$ posterior (these letters together indicate the decreased VB height in each column in descending order [e.g., APM = anterior decrease > posterior decrease > middle decrease]); $\mathrm{VCH}=$ vertebral column height.

safe and acceptable.43,47,49,59 In our study, the spinal cord received a mean dose of $6.5 \mathrm{~Gy}$, a mean maximum dose of $13 \mathrm{~Gy}$, and mean radiation doses of 11.172 and $8.203 \mathrm{~Gy}$ at $0.1-$ and $1-\mathrm{cm}^{3}$ volumes, respectively. None of the patients in our series developed clinical evidence of radiation-induced myelopathy during the follow-up period.

\section{Radiation-Induced Esophagitis, Esophageal Perforation, Stricture, and Fistula}

One of the acute (within 90 days) dose-related complications after SRS near the esophagus is esophagitis and associated dysphagia, whereas long-term and more significant complications include stricture and perforation. In our study, self-limiting dysphagia was noted in 7 (13\%) patients after SRS. Five of these 7 patients had Grade 1 toxicity, and only 2 patients had Grade 2 toxicity. All cases of dysphagia resolved with conservative management.

Amdur et al. ${ }^{2}$ reported dysphagia (Grade 2 toxicity) in $5(83.33 \%)$ of 6 patients who underwent SRS for a cervicothoracic tumor. Studies have found various threshold volumes for esophageal irradiation that correlate with esophageal toxicity. ${ }^{35,38}$ Yamada et al.$^{59}$ reported radiationinduced Grade 2 esophagitis in 2 patients (of a total of 93) and a tracheoesophageal fistula in 1 patient $(9$ months after RT) with spinal metastasis. The authors did not report any difference in esophageal dosimetry based on toxicity; however, a patient who developed a fistula while also on doxorubicin-based chemotherapy ultimately required surgical intervention for this complication..$^{59}$

In our study, dysphagia after SRS was noted after a mean maximum dose received by the esophagus of 13.8 Gy. Furthermore, an esophageal stricture developed in 1 patient (1.79\%) after SRS to the T-1 vertebral level. This patient had undergone previous T-1 corpectomy and anterior cervical plating from C-7 to T-2 with posterior cervical fusion and experienced persistent pain and dysphagia after surgery. The previous surgery, radiation, and infection might have compromised tissue vascularity, which was exacerbated further by the SRS and led to these complications.

In general, the volume of esophagus that receives $>$ 40-50 Gy of radiation has a higher likelihood to develop radiation-induced toxicity (acute esophagitis); therefore, care should be taken to avoid high-dose hypofractionation therapy to this small regional volume..$^{54,55}$ Reports from the Radiation Therapy Oncology Group (RTOG) 0236 and 0631 trials recommend doses of 9 Gy per fraction (27 Gy total) for stereotactic body radiotherapy in lung/thoracic cancer fields and a single-fraction dose of 16 Gy during spine SRS to prevent esophageal toxicity (Table 6). ${ }^{44,48}$ It is unclear why our patient developed a stricture while receiving a maximum mean dose of $13.8 \mathrm{~Gy}$ to the esophagus. Previous surgery in this patient might have compromised

TABLE 6. Comparison of point maximum radiation dose used in this series and recommended RTOG 0631 constraints

\begin{tabular}{lcc}
\hline \multicolumn{1}{c}{ OAR } & $\begin{array}{c}\text { Mean Max Dose (Gy) } \\
\text { Used in This Series }\end{array}$ & $\begin{array}{c}\text { Vol }\left(<0.035 \mathrm{~cm}^{3}\right) \text { Max } \\
\text { Dose (Gy) per RTOG 0631 }\end{array}$ \\
\hline Spinal cord & 13.060 & 14 \\
\hline Brachial plexus & 17.016 & 17.5 \\
\hline Larynx & 11.102 & 20.2 \\
\hline Trachea & 9.575 & 20.2 \\
\hline Esophagus & 13.875 & 16 \\
\hline
\end{tabular}


tissue vascularity and left her more vulnerable to develop this toxicity.

\section{Radiation-Induced Laryngeal Toxicity}

Because RT is a commonly used modality for patients with head and neck cancer, we have a good understanding of radiation-related laryngeal toxicity, which includes hoarseness and swallowing difficulties. ${ }^{15}$ Dornfeld et al. ${ }^{13}$ reported that a higher radiation dose ( $>50-66 \mathrm{~Gy}$ ) to OAR in the head and neck region can result in impairment of speech and swallowing function and weight loss 1 year after EBRT. Levendag et al. ${ }^{33}$ also reported a $23 \%$ incidence of severe dysphagia after IMRT in 81 patients with oropharyngeal squamous cell carcinoma. These authors reported an increase in the probability of dysphagia of $19 \%$ with each additional $10 \mathrm{~Gy}$ (> $50 \mathrm{~Gy}$ ) after radiation to oropharyngeal muscles. ${ }^{33}$ Another study reported an increased incidence of aspiration and esophageal stricture after $\geq 50$ Gy of radiation to the larynx and inferior constrictor muscles, respectively, in 96 patients with head and neck cancer. ${ }^{8}$ Because all of these studies focused on laryngeal toxicity after EBRT, there is a paucity of data regarding laryngeal toxicity after SRS. The results of our study provide insight into the dose received by the larynx and radiation-induced toxicity to this organ in patients with a cervicothoracic tumor.

In our study, hoarseness after SRS was noted in $1(2 \%)$ patient, and the mean maximum dose received by the larynx was $11.1 \mathrm{~Gy}$. This patient developed hoarseness after SRS to the C-5 spine and had undergone previous EBRT and a corpectomy with fusion in the same region. Factors such as pre-SRS surgery and EBRT might need to be considered when deciding on SRS-dosing strategies for such patients.

\section{Radiation-Induced Brachial Plexopathy}

The majority of data available in terms of brachial plexopathy derives from patients treated for breast cancer, apical lung cancer, or head and neck cancer with larger radiation fields using EBRT. The incidence of brachial plexopathy has been reported to range between $1 \%$ and $22 \%$ in patients who received a supraclavicular radiation field dose of 45-60 Gy. 4,6,10,30,39,51,52 It should be noted that the majority of these patients had undergone previous surgery in the region with concomitant chemotherapy., 4,6,39,51 Chen et al. ${ }^{10}$ reported a $12 \%$ incidence of brachial plexopathy in 330 patients with head and neck cancer (median radiation dose $66 \mathrm{~Gy}$; range 50-74 Gy). In addition, they reported that previous neck dissection, a higher radiation dose, and concurrent chemotherapy were significantly associated with plexopathy. Similarly, Kori et al. ${ }^{30}$ reported a higher incidence of plexopathy in patients who received a $>$ 60-Gy radiation dose. Radiation injury involved the upper trunk (C-5/6) and was also associated with lymphedema in these patients. ${ }^{29}$ RTOG 0236 used 24 Gy in 3 fractions and RTOG 0631 used 17.5 Gy in a single fraction as upper limits for brachial plexus during spine SRS; Grade 3 toxicity was an end point. ${ }^{41,44}$

In our study, the maximum dose to the brachial plexus (mean maximum dose $17 \mathrm{~Gy}$ ) was well below the threshold level, and no clinical evidence of toxicity was found.
Although there was no evidence of persistent neuropathic pain (suggestive of brachial plexopathy) in our study, 9\% (5) of our patients reported a transient increase in their radiculopathy symptoms after SRS. Also, we noted that the maximum dose to the brachial plexus showed a trend toward significance $(\mathrm{p}=0.066)$ in patients with post-SRS worsening of pain or painful radiculopathy. However, this complication might also be attributed to the proximity of the tumor to plexus nerve roots and a transient increase in tumor edema after SRS consistent with the fact that pain resolved in all these patients with a short course of steroids within 1-14 days of treatment.

\section{Vertebral Compression Fracture}

In our study, de novo and progressive VCFs were noted in $3 \%$ and $4 \%$ of vertebral segments, respectively, after SRS. Two patients with no significant compression before SRS progressed to Grade 3 compression after SRS, and another patient progressed from no compression to Grade 2 compression after SRS. Sahgal et al. ${ }^{45}$ reported 4.9\% (20 of 410) and 9\% (37 of 410) incidences of de novo and progressive VCF, respectively, after SRS in 252 patients (410 spinal segments). Their study identified a higher radiation dose (>20 Gy/fraction), presence of a lytic spine lesion with deformity, and pre-SRS VCF as significant predictors of VCF after radiosurgery. ${ }^{45}$ The lower incidence of VCFs noted in our study can be attributed to lower radiation doses and lesions localized to the cervicothoracic region. In addition, $71 \%$ of the patients were noted to have a VCF (either de novo or progression) within 4 months of treatment in our series, which is concordant with the incidence of $65 \%$ within 4 months reported by Sahgal et al. ${ }^{45}$ Rose et al. ${ }^{41}$ reported a VCF rate of $38 \%$ (27 of 71 vertebral sites) in their study, and they identified thoracolumbar lytic pathology and treatments prescribing higher radiation doses as risk factors for VCF.

To our knowledge, this is also the first study to have formally evaluated and categorized the pattern (anterior, middle, or posterior $\mathrm{VB}$ ) and region of progression of $\mathrm{VCF}$ after SRS. We noted the highest post-SRS fracture incidence or progression in the posterior part of the VB.

In terms of dose efficacy, our previous studies found a tumor-control rate of $>85 \%{ }^{24,31}$ and unadjusted painrelief rate of $87 \%$ at 9 months after SRS. ${ }^{5}$ Our current study found that at the doses prescribed at the Cleveland Clinic, no significant (Grade 4/5) radiation-induced toxicities to surrounding OAR were noted, and only 1 Grade 3 toxicity (esophageal stricture) was identified. It should be noted that the low toxicity rate observed in this study was achieved while keeping the maximum point doses to the OAR evaluated near or below the single-fraction constraints recommended by the RTOG 0631 report (Table 6).

\section{Limitations}

The limitations of our study include the relatively small heterogeneous patient cohort $(n=56)$ and its retrospective nature. In addition, how specific factors such as antecedent surgery and EBRT can also affect the sensitivity of OAR to radiation injury in the cervicothoracic region remains to be determined and requires a larger series for evaluation. 


\section{Conclusions}

The results of our study provide insight into the complications and radiation-related toxicity to adjacent OAR after SRS to cervicothoracic tumors. According to results of our analysis of dosimetry to various OAR, radiation doses used for single-fraction SRS treatment at the Cleveland Clinic (median 16 Gy) are safe and well tolerated. These preliminary data provide a basis for future studies and dosing limits for patients undergoing SRS to lesions in the cervicothoracic spinal region. To our knowledge, this is the first study to correlate the effects of single-fraction spine SRS to the anatomical structures in the cervicothoracic region and provide guidance for the design of future clinical trials. Randomized controlled studies aimed at validating the efficacy and toxicity profiles of SRS treatment regimens are needed.

\section{References}

1. Adams JE, Lenchik L, Roux C, Genant HK: Vertebral Fracture Initiative. Part II. Radiological Assessment of Vertebral Fracture. (https://www.iofbonehealth.org/sites/ default/files/PDFs/Vertebral\%20Fracture\%20Initiative/IOF VFI-Part_II-Manuscript.pdf ) [Accessed November 16, 2016]

2. Amdur RJ, Bennett J, Olivier K, Wallace A, Morris CG, Liu $\mathrm{C}$, et al: A prospective, phase II study demonstrating the potential value and limitation of radiosurgery for spine metastases. Am J Clin Oncol 32:515-520, 2009

3. Atkinson TM, Ryan SJ, Bennett AV, Stover AM, Saracino RM, Rogak LJ, et al: The association between clinicianbased common terminology criteria for adverse events (CTCAE) and patient-reported outcomes (PRO): a systematic review. Support Care Cancer 24:3669-3676, 2016

4. Bajrovic A, Rades D, Fehlauer F, Tribius S, Hoeller U, Rudat $\mathrm{V}$, et al: Is there a life-long risk of brachial plexopathy after radiotherapy of supraclavicular lymph nodes in breast cancer patients? Radiother Oncol 71:297-301, 2004

5. Balagamwala EH, Angelov L, Koyfman SA, Suh JH, Reddy CA, Djemil T, et al: Single-fraction stereotactic body radiotherapy for spinal metastases from renal cell carcinoma. J Neurosurg Spine 17:556-564, 2012

6. Ballo MT, Strom EA, Zagars GK, Bedikian AY, Prieto VG, Mansfield PF, et al: Adjuvant irradiation for axillary metastases from malignant melanoma. Int J Radiat Oncol Biol Phys 52:964-972, 2002

7. Bate BG, Khan NR, Kimball BY, Gabrick K, Weaver J: Stereotactic radiosurgery for spinal metastases with or without separation surgery. J Neurosurg Spine 22:409-415, 2015

8. Caglar HB, Tishler RB, Othus M, Burke E, Li Y, Goguen L, et al: Dose to larynx predicts for swallowing complications after intensity-modulated radiotherapy. Int J Radiat Oncol Biol Phys 72:1110-1118, 2008

9. Cannon DM, Lee NY: Recurrence in region of spared parotid gland after definitive intensity-modulated radiotherapy for head and neck cancer. Int J Radiat Oncol Biol Phys 70:660-665, 2008

10. Chen AM, Hall WH, Li J, Beckett L, Farwell DG, Lau DH, et al: Brachial plexus-associated neuropathy after high-dose radiation therapy for head-and-neck cancer. Int J Radiat Oncol Biol Phys 84:165-169, 2012

11. Cox BW, Spratt DE, Lovelock M, Bilsky MH, Lis E, Ryu S, et al: International Spine Radiosurgery Consortium consensus guidelines for target volume definition in spinal stereotactic radiosurgery. Int J Radiat Oncol Biol Phys 83:e597e605, 2012

12. Dirix P, Nuyts S: Evidence-based organ-sparing radiotherapy in head and neck cancer. Lancet Oncol 11:85-91, 2010
13. Dornfeld K, Simmons JR, Karnell L, Karnell M, Funk G, Yao M, et al: Radiation doses to structures within and adjacent to the larynx are correlated with long-term diet- and speech-related quality of life. Int J Radiat Oncol Biol Phys 68:750-757, 2007

14. Eisbruch A, Schwartz M, Rasch C, Vineberg K, Damen E, Van As CJ, et al: Dysphagia and aspiration after chemoradiotherapy for head-and-neck cancer: which anatomic structures are affected and can they be spared by IMRT? Int J Radiat Oncol Biol Phys 60:1425-1439, 2004

15. Fung K, Yoo J, Leeper HA, Bogue B, Hawkins S, Hammond JA, et al: Effects of head and neck radiation therapy on vocal function. J Otolaryngol 30:133-139, 2001

16. Gerszten PC, Burton SA, Ozhasoglu C, Welch WC: Radiosurgery for spinal metastases: clinical experience in 500 cases from a single institution. Spine (Phila Pa 1976) 32:193-199, 2007

17. Gibbs IC, Patil C, Gerszten PC, Adler JR Jr, Burton SA: Delayed radiation-induced myelopathy after spinal radiosurgery. Neurosurgery 64 (2 Suppl):A67-A72, 2009

18. Hall EJ: A radiation biologist looks to the future. Int J Radiat Oncol Biol Phys 46:1-2, 2000

19. Hall EJ: Radiation biology. Cancer 55 (9 Suppl):2051-2057, 1985

20. Hall WH, Guiou M, Lee NY, Dublin A, Narayan S, Vijayakumar S, et al: Development and validation of a standardized method for contouring the brachial plexus: preliminary dosimetric analysis among patients treated with IMRT for head-and-neck cancer. Int J Radiat Oncol Biol Phys 72:1362-1367, 2008

21. Hamilton AJ, Lulu BA, Fosmire H, Gossett L: LINAC-based spinal stereotactic radiosurgery. Stereotact Funct Neurosurg 66:1-9, 1996

22. Harari PM: Beware the swing and a miss: baseball precautions for conformal radiotherapy. Int J Radiat Oncol Biol Phys 70:657-659, 2008

23. Harel R, Angelov L: Spine metastases: current treatments and future directions. Eur J Cancer 46:2696-2707, 2010

24. Harel R, Emch T, Chao S, Elson P, Krishnaney A, Djemil $\mathrm{T}$, et al: Quantitative evaluation of local control and wound healing following surgery and stereotactic spine radiosurgery for spine tumors. World Neurosurg 87:48-54, 2016

25. Hayat MJ, Howlader N, Reichman ME, Edwards BK: Cancer statistics, trends, and multiple primary cancer analyses from the Surveillance, Epidemiology, and End Results (SEER) Program. Oncologist 12:20-37, 2007

26. Jabbari S, Gerszten PC, Ruschin M, Larson DA, Lo SS, Sahgal A: Stereotactic body radiotherapy for spinal metastases: practice guidelines, outcomes, and risks. Cancer J 22:280289, 2016

27. Jin JY, Chen Q, Jin R, Rock J, Anderson J, Li S, et al: Technical and clinical experience with spine radiosurgery: a new technology for management of localized spine metastases. Technol Cancer Res Treat 6:127-133, 2007

28. Jin JY, Ryu S, Rock J, Faber K, Chen Q, Ajlouni M, et al: Evaluation of residual patient position variation for spinal radiosurgery using the Novalis image guided system. Med Phys 35:1087-1093, 2008

29. Klimo P Jr, Thompson CJ, Kestle JR, Schmidt MH: A metaanalysis of surgery versus conventional radiotherapy for the treatment of metastatic spinal epidural disease. Neuro Oncol 7:64-76, 2005

30. Kori SH, Foley KM, Posner JB: Brachial plexus lesions in patients with cancer: 100 cases. Neurology 31:45-50, 1981

31. Koyfman SA, Djemil T, Burdick MJ, Woody N, Balagamwala $\mathrm{EH}$, Reddy CA, et al: Marginal recurrence requiring salvage radiotherapy after stereotactic body radiotherapy for spinal metastases. Int J Radiat Oncol Biol Phys 83:297-302, 2012

32. Laufer I, Iorgulescu JB, Chapman T, Lis E, Shi W, Zhang Z, 
et al: Local disease control for spinal metastases following "separation surgery" and adjuvant hypofractionated or highdose single-fraction stereotactic radiosurgery: outcome analysis in 186 patients. J Neurosurg Spine 18:207-214, 2013

33. Levendag PC, Teguh DN, Voet P, van der Est H, Noever I, de Kruijf WJ, et al: Dysphagia disorders in patients with cancer of the oropharynx are significantly affected by the radiation therapy dose to the superior and middle constrictor muscle: a dose-effect relationship. Radiother Oncol 85:64-73, 2007

34. Lovelock DM, Zhang Z, Jackson A, Keam J, Bekelman J, Bilsky M, et al: Correlation of local failure with measures of dose insufficiency in the high-dose single-fraction treatment of bony metastases. Int J Radiat Oncol Biol Phys 77:12821287,2010

35. Marks LB, Yorke ED, Jackson A, Ten Haken RK, Constine LS, Eisbruch A, et al: Use of normal tissue complication probability models in the clinic. Int J Radiat Oncol Biol Phys 76 (3 Suppl):S10-S19, 2010

36. Mendenhall WM, Mancuso AA: Radiotherapy for head and neck cancer-is the "next level" down? Int J Radiat Oncol Biol Phys 73:645-646, 2009

37. Miller JA, Balagamwala EH, Angelov L, Suh JH, Djemil T, Magnelli A, et al: Stereotactic radiosurgery for the treatment of primary and metastatic spinal sarcomas. Technol Cancer Res Treat [epub ahead of print], 2016

38. Miller JA, Balagamwala EH, Angelov L, Suh JH, Rini B, Garcia JA, et al: Spine stereotactic radiosurgery with concurrent tyrosine kinase inhibitors for metastatic renal cell carcinoma. J Neurosurg Spine [epub ahead of print July 8, 2016. DOI: 10.3171/2016.4.SPINE16229]

39. Olsen NK, Pfeiffer P, Johannsen L, Schrøder H, Rose C: Radiation-induced brachial plexopathy: neurological followup in 161 recurrence-free breast cancer patients. Int J Radiat Oncol Biol Phys 26:43-49, 1993

40. Rock JP, Ryu S, Yin FF: Novalis radiosurgery for metastatic spine tumors. Neurosurg Clin N Am 15:503-509, 2004

41. Rose PS, Laufer I, Boland PJ, Hanover A, Bilsky MH, Yamada J, et al: Risk of fracture after single fraction image-guided intensity-modulated radiation therapy to spinal metastases. J Clin Oncol 27:5075-5079, 2009

42. Ryu S, Fang Yin F, Rock J, Zhu J, Chu A, Kagan E, et al: Image-guided and intensity-modulated radiosurgery for patients with spinal metastasis. Cancer 97:2013-2018, 2003

43. Ryu S, Jin JY, Jin R, Rock J, Ajlouni M, Movsas B, et al: Partial volume tolerance of the spinal cord and complications of single-dose radiosurgery. Cancer 109:628-636, 2007

44. Ryu S, Pugh SL, Gerszten PC, Yin FF, Timmerman RD, Hitchcock YJ, et al: RTOG 0631 phase $2 / 3$ study of image guided stereotactic radiosurgery for localized (1-3) spine metastases: phase 2 results. Pract Radiat Oncol 4:76-81, 2014

45. Sahgal A, Atenafu EG, Chao S, Al-Omair A, Boehling N, Balagamwala EH, et al: Vertebral compression fracture after spine stereotactic body radiotherapy: a multi-institutional analysis with a focus on radiation dose and the spinal instability neoplastic score. J Clin Oncol 31:3426-3431, 2013

46. Shin JH, Chao ST, Angelov L: Stereotactic radiosurgery for spinal metastases: update on treatment strategies. J Neurosurg Sci 55:197-209, 2011

47. Swift PS: Radiation for spinal metastatic tumors. Orthop Clin North Am 40:133-144, vii, 2009

48. Timmerman R, Paulus R, Galvin J, Michalski J, Straube W, Bradley J, et al: Stereotactic body radiation therapy for inoperable early stage lung cancer. JAMA 303:1070-1076, 2010

49. Timmerman RD: An overview of hypofractionation and introduction to this issue of seminars in radiation oncology. Semin Radiat Oncol 18:215-222, 2008

50. Toussaint A, Richter A, Mantel F, Flickinger JC, Grills IS, Tyagi N, et al: Variability in spine radiosurgery treatment planning-results of an international multi-institutional study. Radiat Oncol 11:57, 2016

51. Uematsu M, Bornstein BA, Recht A, Abner A, Come SE, Shulman LN, et al: Long-term results of post-operative radiation therapy following mastectomy with or without chemotherapy in stage I-III breast cancer. Int J Radiat Oncol Biol Phys 25:765-770, 1993

52. Uematsu M, Kondo M, Amemiya A, Hashimoto S, Ikari S, Izumi K, et al: [Long-term follow-up after tumorectomy and irradiation for breast cancer.] Gan No Rinsho 34:167-173, 1988 (Jpn)

53. Veldeman L, Madani I, Hulstaert F, De Meerleer G, Mareel M, De Neve W: Evidence behind use of intensity-modulated radiotherapy: a systematic review of comparative clinical studies. Lancet Oncol 9:367-375, 2008

54. Werner-Wasik M, Yorke E, Deasy J, Nam J, Marks LB: Radiation dose-volume effects in the esophagus. Int J Radiat Oncol Biol Phys 76 (3 Suppl):S86-S93, 2010

55. Werner-Wasik M, Yu X, Marks LB, Schultheiss TE: Normaltissue toxicities of thoracic radiation therapy: esophagus, lung, and spinal cord as organs at risk. Hematol Oncol Clin North Am 18:131-160, x-xi, 2004

56. White AP, Kwon BK, Lindskog DM, Friedlaender GE, Grauer JN: Metastatic disease of the spine. J Am Acad Orthop Surg 14:587-598, 2006

57. Winstead ER: After treatment: the needs of cancer survivors. NCI Cancer Bull 2:1-2, 2005

58. Wong DA, Fornasier VL, Macnab I: Spinal metastases: the obvious, the occult, and the impostors. Spine (Phila Pa 1976) 15:1-4, 1990

59. Yamada Y, Bilsky MH, Lovelock DM, Venkatraman ES, Toner S, Johnson J, et al: High-dose, single-fraction imageguided intensity-modulated radiotherapy for metastatic spinal lesions. Int J Radiat Oncol Biol Phys 71:484-490, 2008

60. Yin FF, Ryu S, Ajlouni M, Yan H, Jin JY, Lee SW, et al: Image-guided procedures for intensity-modulated spinal radiosurgery. Technical note. J Neurosurg 101 (Suppl 3):419424, 2004

61. Yin FF, Ryu S, Ajlouni M, Zhu J, Yan H, Guan H, et al: A technique of intensity-modulated radiosurgery (IMRS) for spinal tumors. Med Phys 29:2815-2822, 2002

62. Yin FF, Zhu J, Yan H, Gaun H, Hammoud R, Ryu S, et al: Dosimetric characteristics of Novalis shaped beam surgery unit. Med Phys 29:1729-1738, 2002

\section{Disclosures}

Dr. Suh has served as a consultant for Varian Medical Systems.

\section{Author Contributions}

Conception and design: Angelov, Sharma, Rahmathulla. Acquisition of data: Sharma, Bennett, Rahmathulla, Koech, Gregory, Emch, Magnelli, Meola. Analysis and interpretation of data: Sharma, Bennett. Drafting the article: Sharma. Critically revising the article: Angelov, Sharma, Bennett, Rahmathulla, Chao, Gregory, Emch, Magnelli, Meola, Suh. Reviewed submitted version of manuscript: Sharma, Bennett, Rahmathulla, Koech, Gregory, Emch, Magnelli, Meola, Suh. Approved the final version of the manuscript on behalf of all authors: Angelov. Statistical analysis: Sharma. Administrative/technical/material support: Angelov, Chao, Suh. Study supervision: Angelov, Chao, Suh.

\section{Correspondence}

Lilyana Angelov, Rose Ella Burkhardt Brain Tumor and NeuroOncology Center, Cleveland Clinic, 9500 Euclid Ave., S73, Cleveland, OH 44195. email: angelol@ccf.org. 